\title{
A comprehensive model to address reproductive health and family planning needs of factory workers in Port Said [Arabic]
}

Evidence Project

Follow this and additional works at: https://knowledgecommons.popcouncil.org/departments_sbsr-rh How does access to this work benefit you? Let us know!

\section{Recommended Citation}

Evidence Project. 2021. "A comprehensive model to address reproductive health and family planning needs of factory workers in Port Said [Arabic]," infographic. Washington, DC: Population Council, The Evidence Project. 


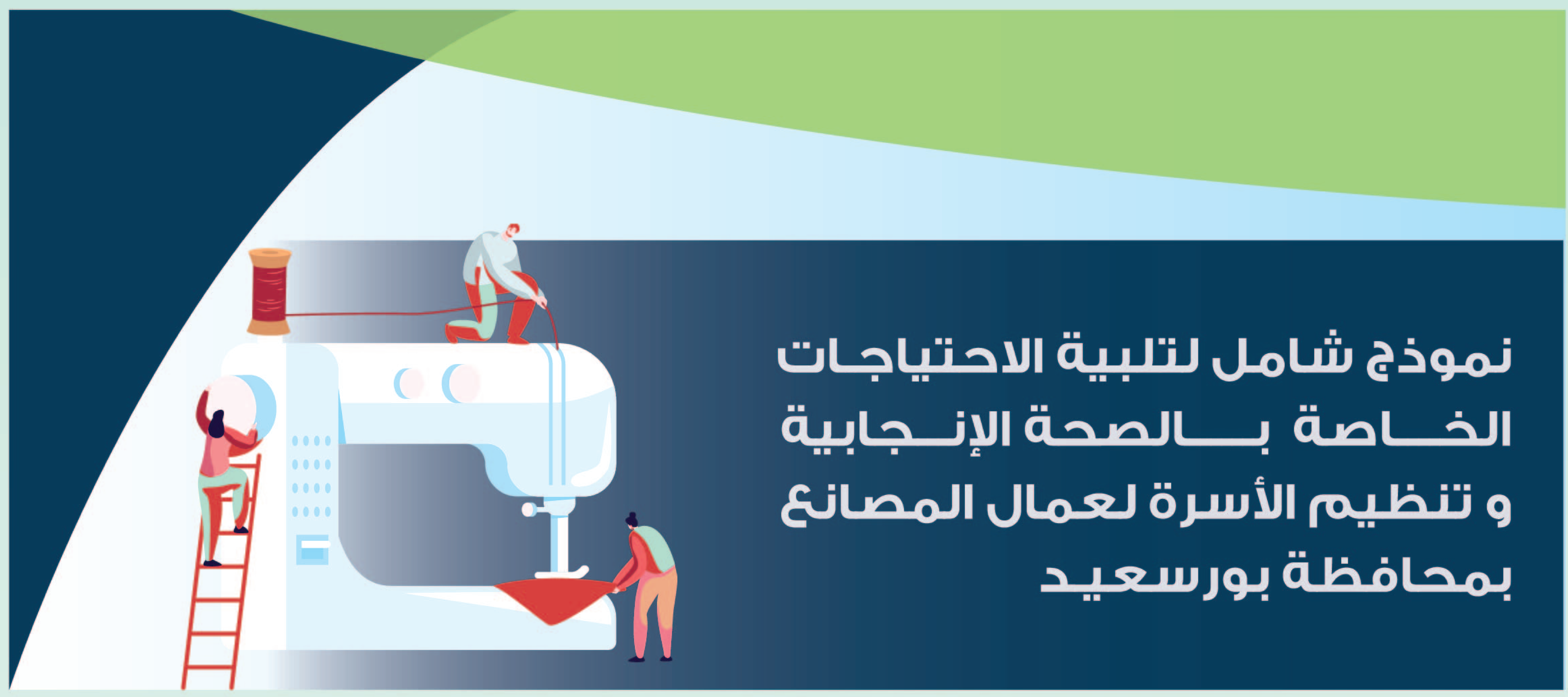

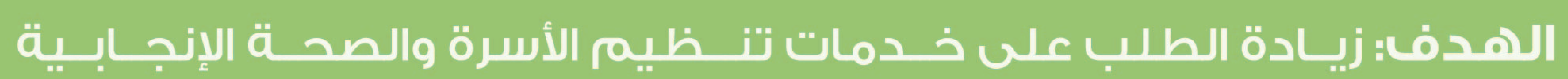

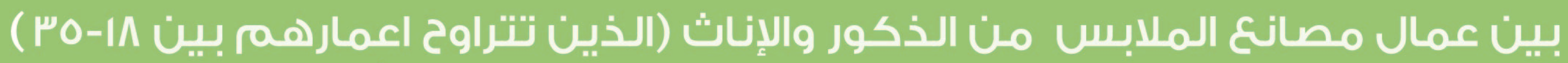

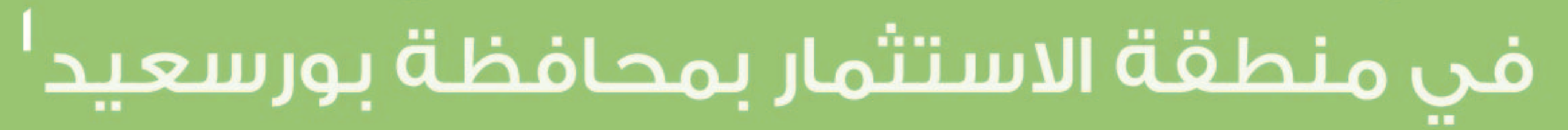

\section{التــــدخــات}
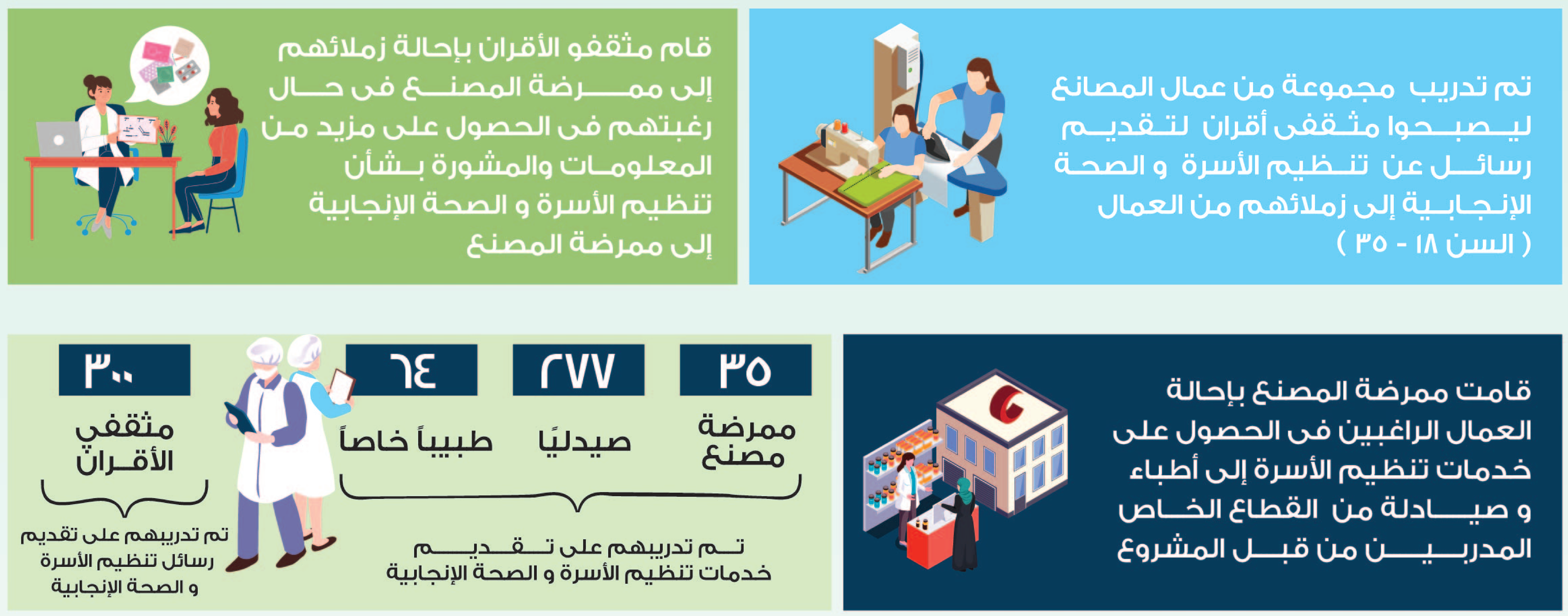

قامم مثثقفو الأقران بـــــر الرسائل الصحيـة إلى ما يقرب

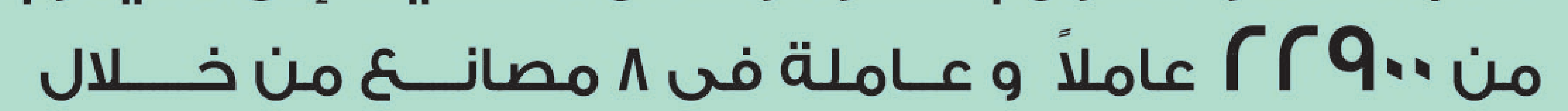

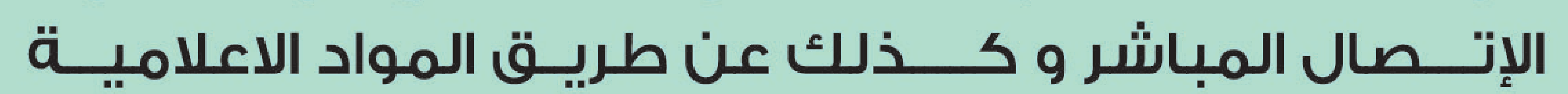

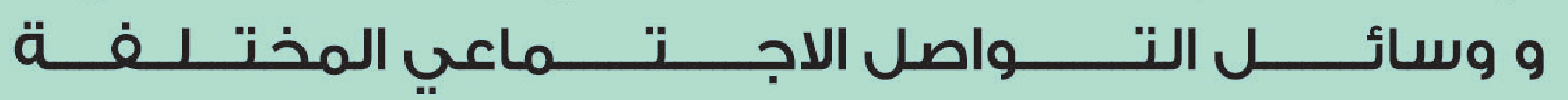

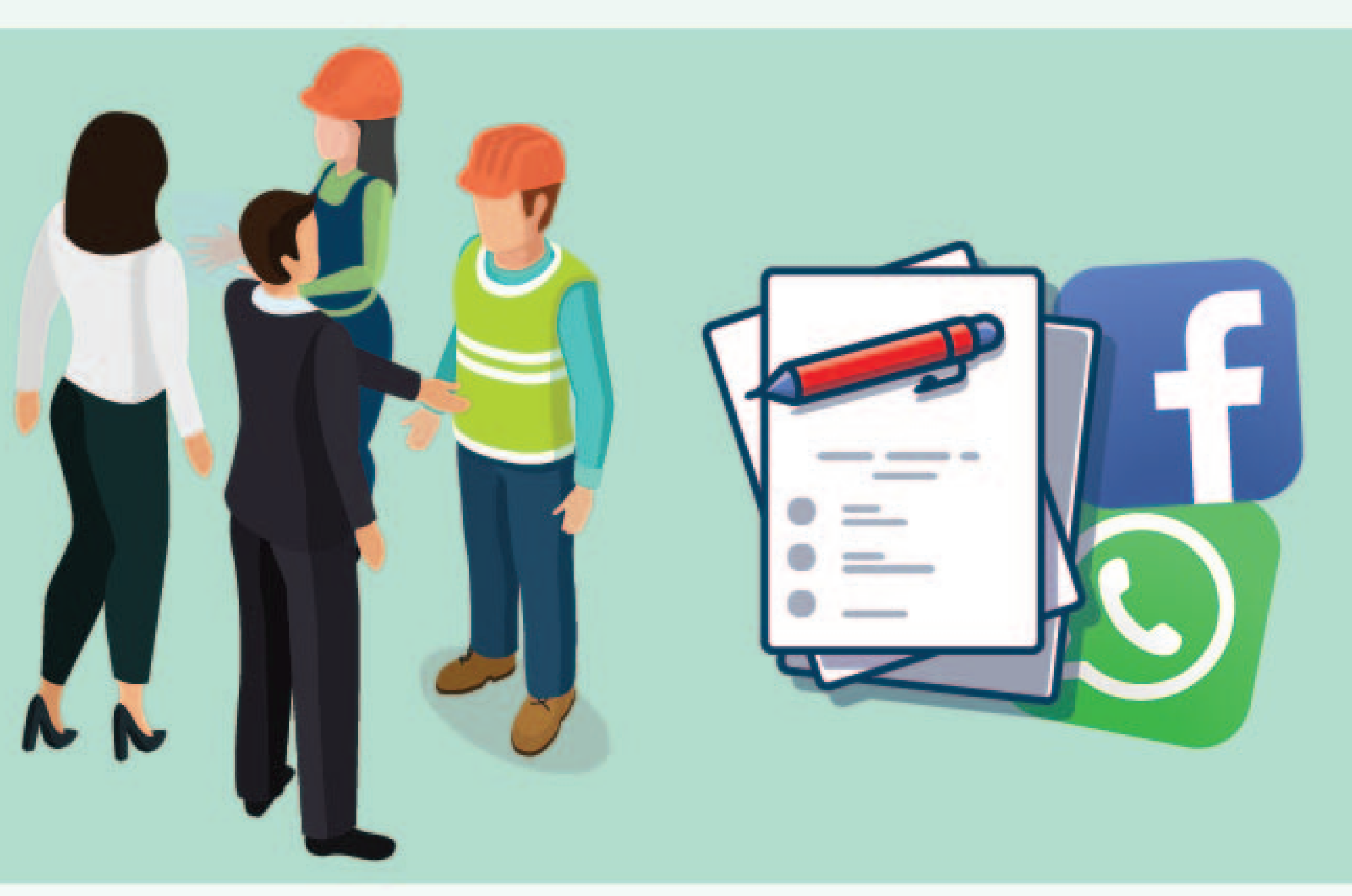




\section{وجهات نظر المشاركين فن البرنامه'}

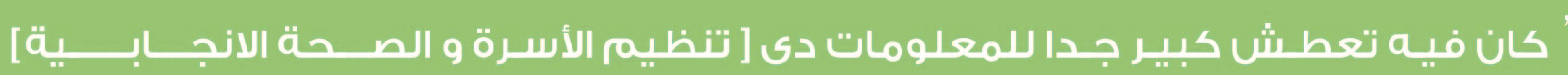

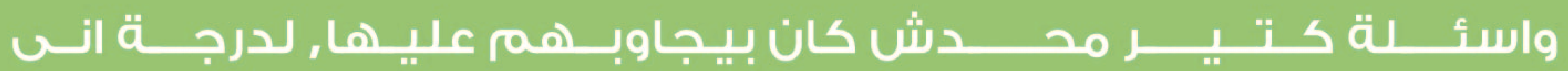

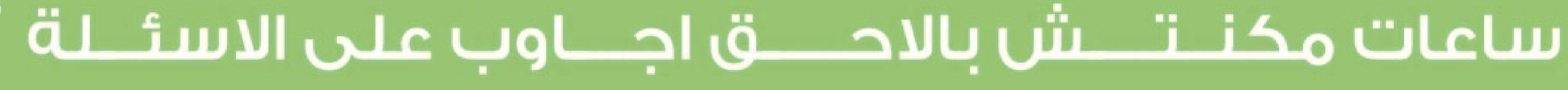

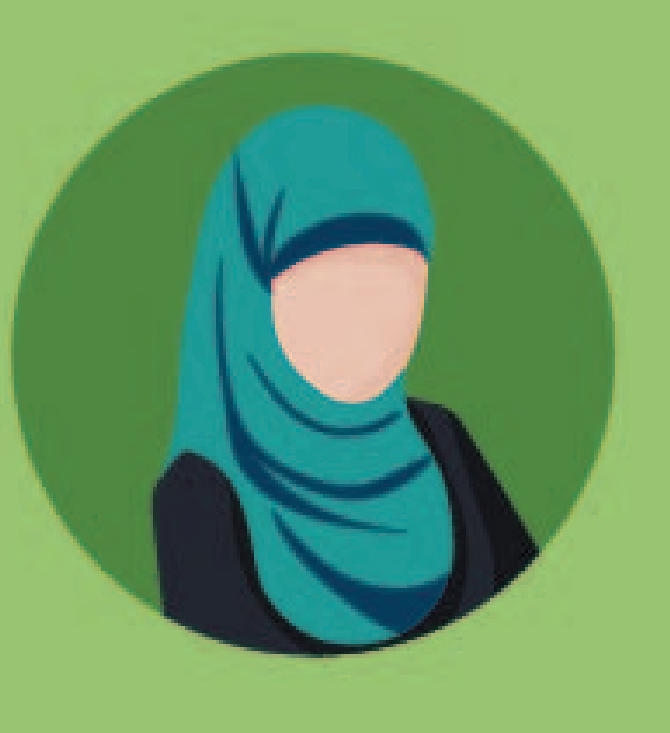

مثقفة آقران, rrr سنة

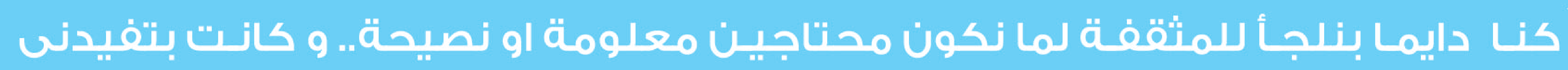

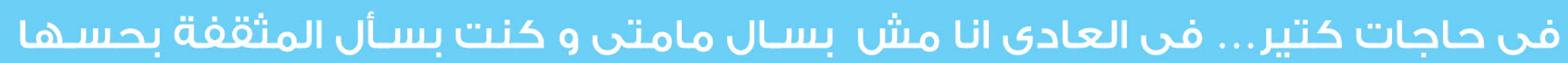

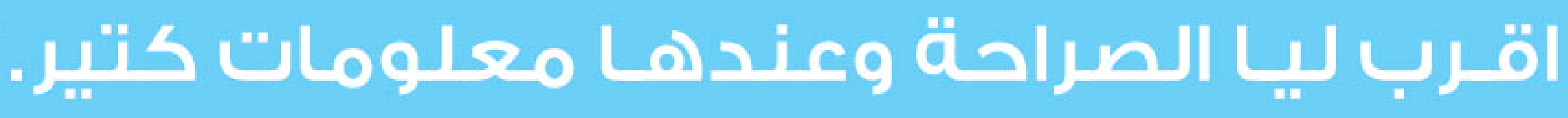

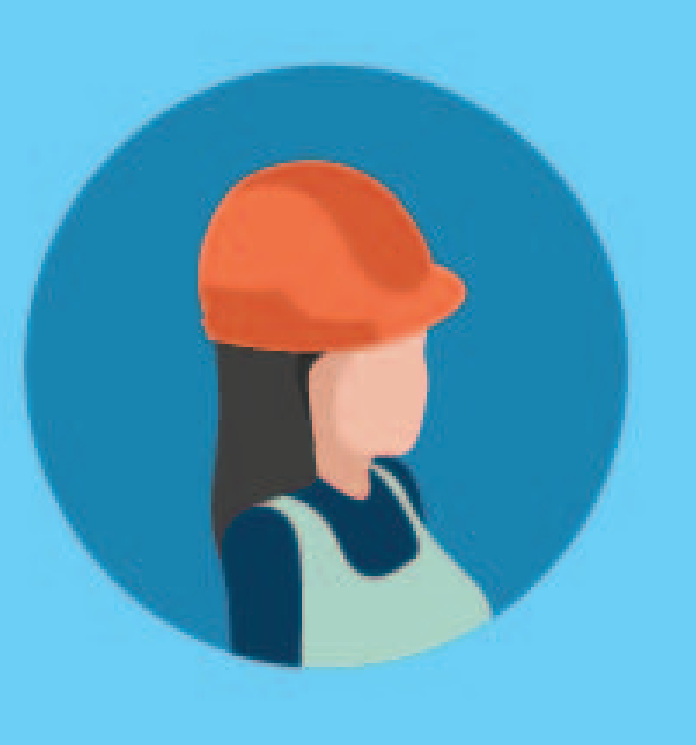

عاملة بأحد المصانع الشريكه, ro سنة

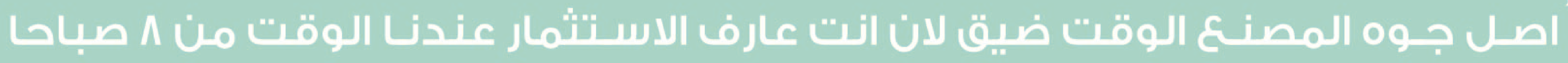

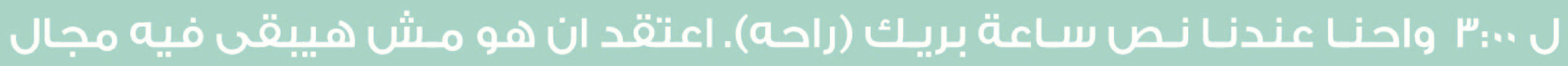

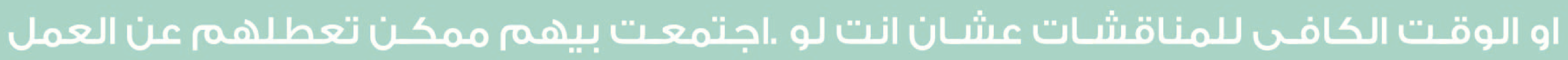

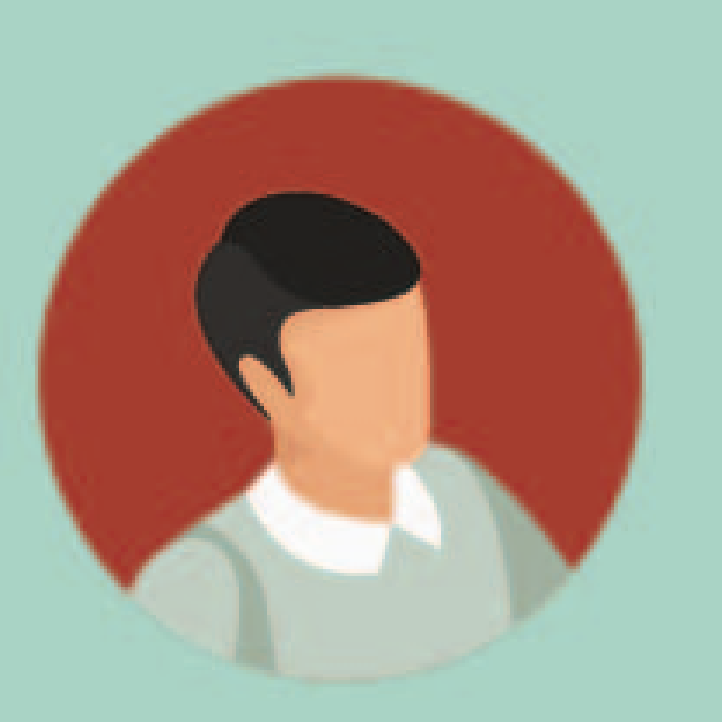

مثقفف آقران, م سنة

كوحـدات انتاجيـه صعـب ان حـــ يعطل حركـه الانتاج او تعطيل المنتجه لمدة نصف سـاعة

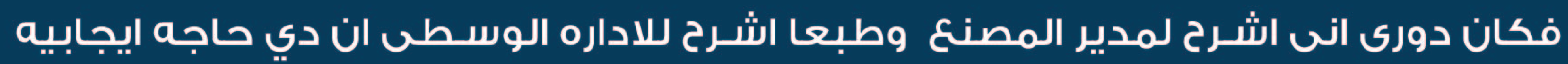

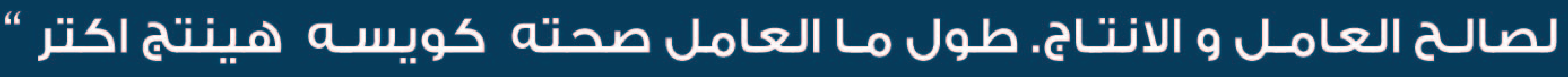

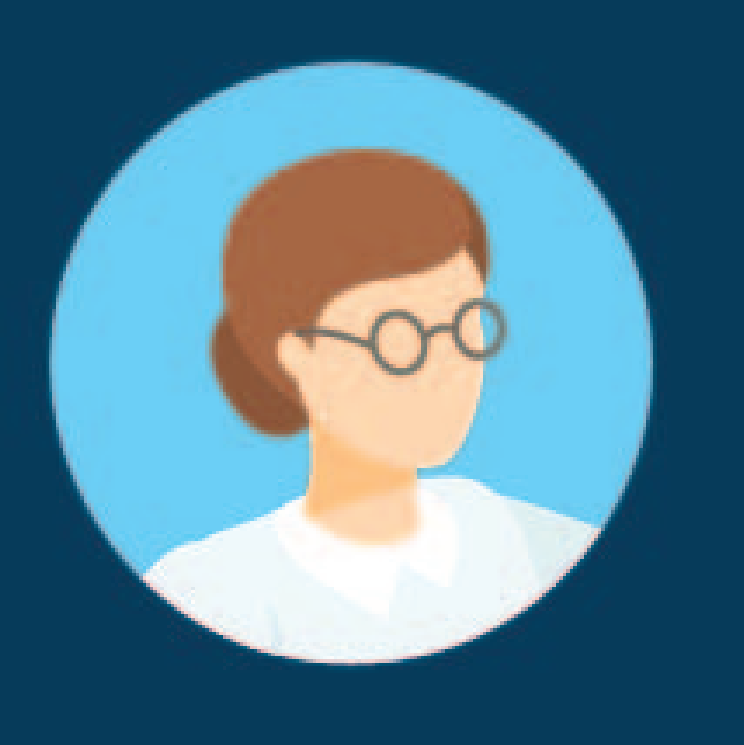

مشرفة بأحد المصانع الشريكة , ^ سنة

يمكن تعزيز الإتصال المباشر بالمصادر الإعلامية ووسائل

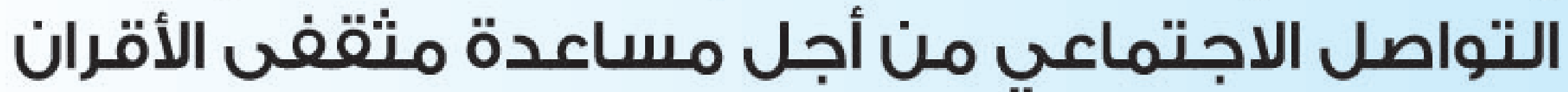

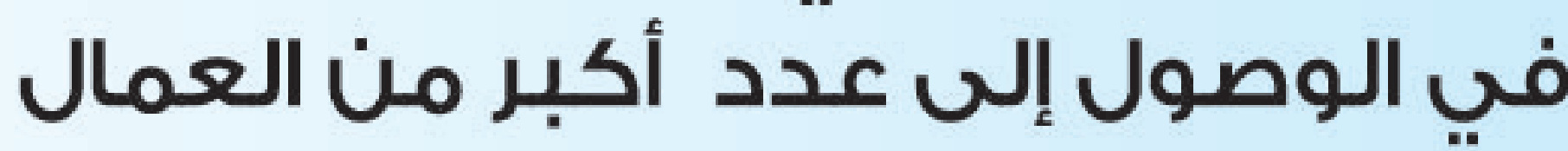

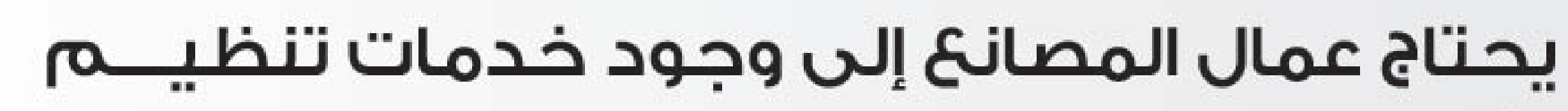

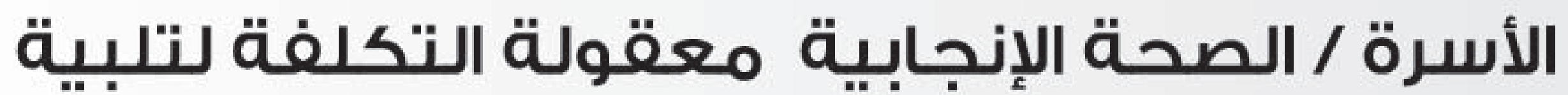

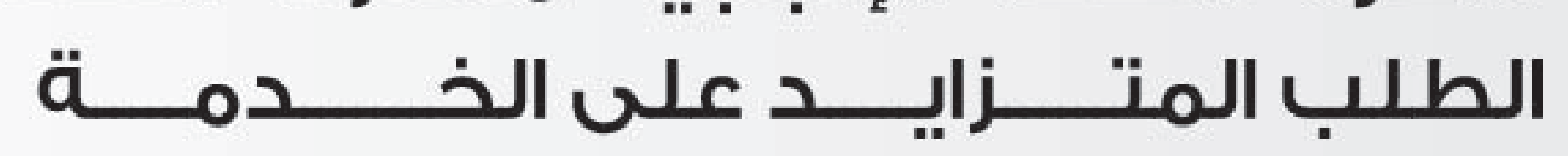

يعد دمه معلومات وخدمات تنظيم الأسرة / الصحة

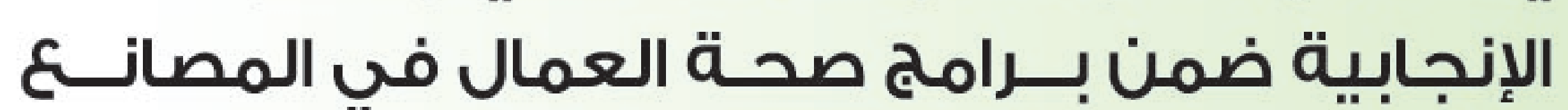

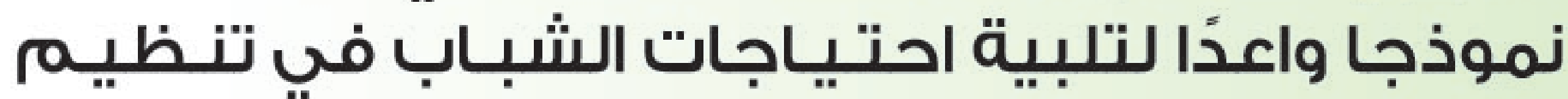

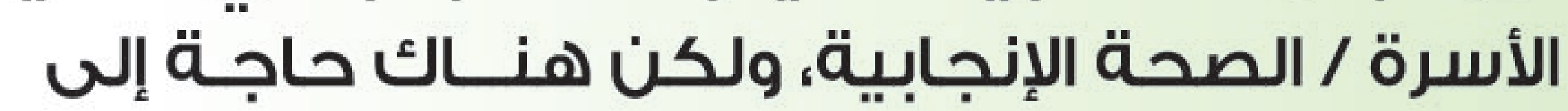

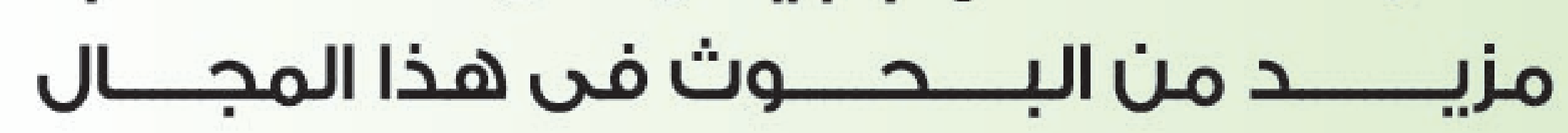

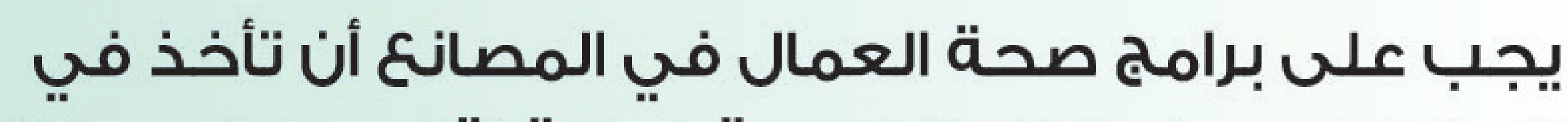
الاعتبار قيود الوقت والطبيعة المتنقلة لعمالعال المصانئع

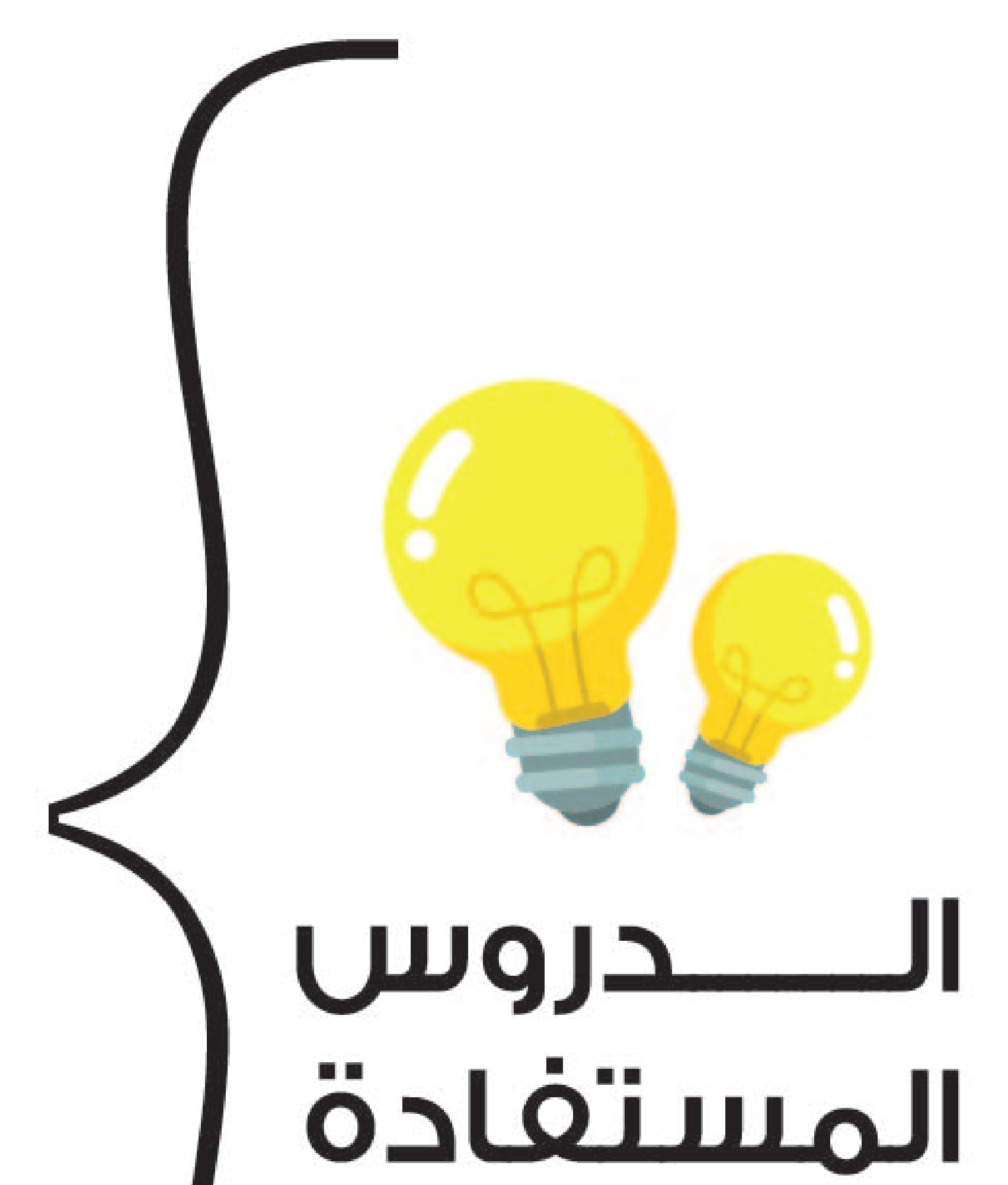

المستفادة الـروة

'لمزيد من المعلومات عن اثر التدخلات على المعرفة واتجاهات الرأى واستخدام وسائل تنظيم الاسرة يمكن الاطلاع على المرجع التالى ABDEL-TAWAB, NAHLA, NORHAN BADER, ELIZABETH TOBEY, AND APARNA JAIN. 2020، “TWO IMPLEMENTATION MODELS OF WORKERS' HEALTH EDUCATION PROGRAMS IN EGYPT WHAT WORKS? WHAT DOESN'T WORK?” RESEARCH BRIEF. WASHINGTON DC: POPULATION COUNCIL, THE EVIDENCE PROJECT

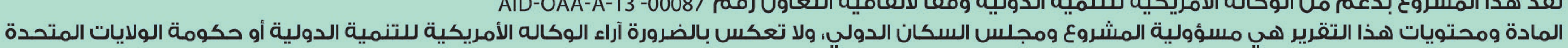

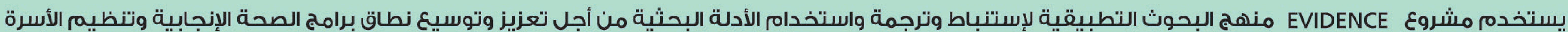

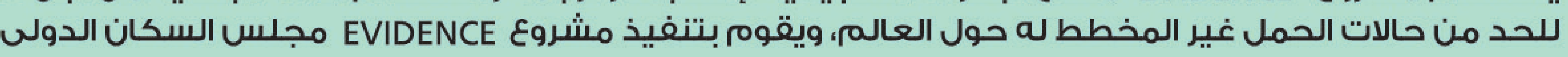

